\title{
HLA-B alleles and complotypes in Mexican patients with seronegative spondyloarthropathies
}

Department of Immunology and Rheumatology, Instituto Nacional de la Nutrición Salvador Zubirán,

Tlalpan, México

G Vargas-Alarcón

A García

S Bahena

H Melín-Aldana

$F$ Andrade

G Ibañez-de-Kasep

J Alcocer-Varela

D Alarcón-Segovia

$\mathrm{J}$ Granados

Correspondence to:

Dr Julio Granados,

Department of Immunology

and Rheumatology,

Instituto Nacional de la

Nutrición Salvador Zubirán,

Vasco de Quiroga 15

Tlalpan 14000

México DF, México.

Accepted for publication 16 June 1994

\begin{abstract}
Objectives-To analyse major histocompatibility complex (MHC) haplotypes in Mexican mestizo patients with seronegative spondyloarthropathies (SSpA) and normal controls, to discover if there are other antigens, besides $\mathrm{B27}$, in the HLA region that might show association with the disease.

Methods-The study included 100 Mexican mestizo patients with SSpA and 200 of their first degree relatives. These groups were compared with 85 ethnically matched controls. The class I and class III MHC antigens were obtained by standard methods. The significance of differences between patients and controls was tested by $\chi^{2}$ analysis; linkage disequilibrium among the different alleles in each haplotype was estimated by computing delta values.
\end{abstract}

Results-We found a significantly increased frequency of the HLA-B27 antigen $\left(p_{\text {corr. }}=1 \times 10^{-5}\right.$, odds ratio $(O R)=33.4$, $95 \%$ confidence interval $(\mathrm{CI})=9 \cdot 3-142 \cdot 0)$. In the group of $45 \mathrm{SSpA}$ patients negative for the B27 antigen, independent increased frequencies of HLA-B49 antigen $\left(p_{\text {corr. }}=0 \cdot 03\right.$, OR $\left.\left.=6 \cdot 5,95 \% \mathrm{CI}=1 \cdot 5-32 \cdot 8\right)\right)$ and the FC31 complotype ( $p_{\text {corr. }}=0.04$, $\mathrm{OR}=3 \cdot 7,95 \% \mathrm{CI}=1 \cdot 2-11 \cdot 1)$ were found. Significant delta values were obtained for the $[\mathrm{B27} ; \mathrm{SC30}]$ haplotype $(p=0.0005)$ but not for haplotypes marked by the FC31 complotype. HLA-B antigens on the homologous chromosome in B27 positive patients were mainly HLA-B51 $(18 \%)$ and HLA-B60 (16\%); however, the observed genotypes B27/B51 and B27/B60 were not significantly different than expected from the allele frequencies alone.

Conclusions-These data suggest that in Mexicans additional genes within the MHC region besides the HLA-B27 antigen, might be related to the genetic susceptibility for developing SSpA. Relevant antigens included the HLA-B49 and the FC31 complotype.

(Ann Rheum Dis 1994; 53: 755-758)

The histocompatibility antigen HLA-B27 is strongly associated with ankylosing spondylitis (AS) and related diseases..$^{1-3}$ Over $90 \%$ of the patients with AS, and $60-95 \%$ of the patients with Reiter's syndrome (RS) or associated spondyloarthropathies shared this antigen, compared with $6-8 \%$ of normal White controls. ${ }^{1-4}$ The pathogenic mechanisms responsible for this association and the role of HLA-B27 antigen in the development of these diseases are unknown.

Despite the very close association between B27 and AS, the presence of the antigen does not lead to the development of the disease. Only $1-3 \%$ of B27 positive individuals from the population develop AS. Conversely, a small proportion of AS patients do not carry B27. ${ }^{5}$ This indicates that the antigen alone is neither necessary nor sufficient for the development of the disease.

Structural analysis of the HLA-B27 antigen has revealed the existence of multiple variants, or subtypes, in human populations. Several studies reported no differences in susceptibility to AS among the subtypes; ${ }^{7-9}$ nonetheless, Hill et $a l^{10}$ proposed that the HLA-B ${ }^{\star} 2703$ subtype is not disease associated, thereby accounting for the low incidence of AS and reactive arthritis in West Africa where this subtype is prevalent. However, studies in patients from this ethnic group are needed to support this hypothesis.

It is generally accepted that the HLA-B27 antigen is implicated in disease but it has also been suggested that additional genetic and environmental factors seem to be necessary to confer the susceptibility to AS. ${ }^{7}$ Most efforts to detect additional HLA susceptibility alleles have been focused on individuals who lack the B27 marker. Studies on different ethnic groups have shown that the strength of association in the patients follows the antigen frequency of HLA-B27 in the normal controls; thus in populations with low B27 antigen frequency, for instance Black populations, there are more patients who lack the B27 antigen. ${ }^{11}$ Genetic admixture estimates in Mexican mestizos have shown $56 \%$ of Indian genes, $40 \%$ of White genes and $4 \%$ of Black genes; $; 12-14$ phenotype frequency of HLA-B27 is only 0.035 . This study on Mexican mestizos aimed to detect additional class I or class III MHC genes that might act either independently or in conjunction with B27 to increase the susceptibility to develop seronegative spondyloarthropathies (SSpA). In addition, we looked at the homologous 6th chromosome B locus and complotype alleles in B27 positive patients, because of a recent report of over-representation of B60 on the homologous 6th chromosome in B27 
positive White AS patients. ${ }^{15}$ It appears that instead of B60, some other HLA linked genetic factors might play a role to increase further the susceptibility to the disease.

\section{Subjects and methods}

PATIENTS

We studied 100 consecutive Mexican patients with SSpA (88 men and 12 women) (mean age $=30$ years), seen at the rheumatology outpatient clinic of the Instituto Nacional de la Nutrición Salvador Zubirán in Mexico City. To obtain major histocompatibility complex (MHC) haplotypes, 200 of their first degree relatives were also typed.

According to the European Spondyloarthropathy Study Group criteria, ${ }^{16}$ our patients had inflammatory spinal pain or synovitis (asymmetric or predominantly in the lower limbs) together with at least one of the following clinical criteria: positive family history, urethritis, cervicitis, or acute diarrhoea within one month before arthritis, enthesopathy, sacroiliitis.

From the $100 \mathrm{SSpA}$ patients, 50 fulfilled the New York criteria ${ }^{17}$ for AS, whereas 40 had clinical diagnosis of RS. ${ }^{18}$ Most of them had a non-gonococcal or postvenereal or postenteritic form(s) of the syndrome. The arthritis was not of a psoriatic type, and none of them had clinical manifestations related to inflammatory bowel diseases (Crohn's disease, or ulcerative colitis).

The clinical picture in 10 individuals was not clear enough to discriminate AS or RS, and they were considered as having undifferentiated spondyloarthropathy.

\section{CONTROLS}

Eighty five healthy Mexican individuals from 43 ethnically matched families (only parents were included for purposes of statistical analysis) were used as controls. Control individuals and their last two generations were born in Mexico City.

Serological HLA typing. Venous blood samples were obtained from patients, relatives and controls. Lymphocytes were isolated using a density gradient centrifugation technique. ${ }^{19}$ HLA-B typing was performed in T cells with a standard microlymphocytotoxicity test. ${ }^{20}$ Typing trays were purchased from C-Six Diagnostics (Mequon, WI, USA). Trays consisted of a total of 140 antisera to define 49 specificities from the A, B, and C, HLA loci.

Complement typing. Factor B (BF) typing was carried out by immunofixation after agarose gel electrophoresis of plasma samples ${ }^{21}$ using goat anti-human BF antibodies (Atlantic Antibodies, Stillwater, MN, USA). Neuraminidase-treated plasma samples were subjected to agarose gel electrophoresis and immunofixation with goat anti-human $\mathrm{C} 4$ antibodies (Atlantic Antibodies) for typing of $\mathrm{C} 4 \mathrm{~A}$ and $\mathrm{C} 4 \mathrm{~B}{ }^{22} \mathrm{C} 2$ patterns were generated by isoelectric focusing of serum samples in polyacrylamide gel, and patterns were developed in a C2-sensitive agarose gel containing antibodysensitised sheep erythrocytes. ${ }^{23}$
The nomenclature for $\mathrm{BF}, \mathrm{C} 2$ and $\mathrm{C} 4$ variants has been published previously. ${ }^{21-23}$ Complotypes are given in arbitrary order as BF, C2, C4A and C4B alleles. For example, the most common complotype in healthy Mexicans, SC31, denotes $\mathrm{BF}^{\star} \mathrm{S}, \mathrm{C} 2{ }^{\star} \mathrm{C}$, $\mathrm{C} 4 \mathrm{~A}^{\star} 3, \mathrm{C}^{2} \mathrm{~B}^{\star} 1$.

\section{STATISTICAL ANALYSIS}

The significance of the differences between groups was performed using Mantel-Haenszel $\chi^{2}$ analysis which combined the $2 \times 2$ tables using the EPISTAT statistical program. The $p$ values were corrected by the number of comparisons ( 16 for HLA-B and 8 for complotypes). Relative risks with $95 \%$ confidence interval $(95 \% \mathrm{CI})$ were calculated as odds ratios (OR), also using the Mantel-Haenszel method.

In accordance with Mattiuz et $a l,{ }^{24}$ we calculated the linkage disequilibrium (delta value) as follows:

$$
\text { delta }=\sqrt{\frac{d}{N}}-\sqrt{\frac{b+d}{N} \times \frac{c+d}{N}}
$$

in which $b$ refers to the number of individuals possessing the HLA-B antigen and lacking the complotype one, c lacks the HLA-B antigen and has the complotype one, while d lacks both HLA-B and complotype, and $\mathrm{N}$ is the total number of individuals.

We measured the difference between the frequency with which a pair of alleles has to occur in a single haplotype (expected frequency) and the real combination of both alleles in the studied population (observed frequency), bearing in mind that the individual frequencies are known. The delta value for a combination of phenotypes expresses the differences between the expected frequency and the observed frequency. The statistical significance of the delta value was tested by $\chi^{2}$.

\section{Results}

HLA-B27 POSITIVE PATIENTS

Thirty five of $50(70 \%)$ AS patients, 18 of 40 $(45 \%)$ RS patients and two of $10(20 \%)$ undifferentiated spondyloarthropathy patients were HLA-B27 positive.

Relevant HLA-B alleles in SSpA patients and in normal controls are shown in table 1; patients had a significantly increased frequency of HLAB27 ( $_{\text {corr. }}=1 \times 10^{-5}, \quad \mathrm{OR}=33.4,95 \% \quad \mathrm{CI}=$ 9.3-142). Other HLA-B alleles were equally distributed between patients and controls including the B27 CREG (B7, B22, B42) antigens.

HLA-B antigens on the homologous chromosomes in B27 positive patients were mainly HLAB51 (18\%) and HLA-B60 (16\%); however, the observed genotypes B27/B51 and B27/B60 (observed frequency $=0 \cdot 100$ and 0.090 , respectively) were not significantly different than expected from the allele frequencies alone (expected frequency $=0.059$ and 0.039 , respectively). 
Table 1 also includes the results on complement alleles in patients, where a significant increased frequency of the FC31 complotype $\left(p_{\text {corr. }}=0.04, \quad O R=3.2,95 \% \quad C I=1 \cdot 2-8.3\right)$ is observed. Frequencies of other complotypes in patients and the control group were not statistically different.

Results for the 45 B27-negative patients and comparison with normal controls excluding B27 individuals are shown in table 2 . We found an independent increased frequency of both HLAB49 $\left(p_{\text {corr. }}=0 \cdot 03, \mathrm{OR}=6 \cdot 5,95 \% \mathrm{CI}=1 \cdot 5-32 \cdot 8\right)$ and the FC31 complotype ( $\mathrm{p}_{\text {corr. }}=0.04$, $\mathrm{OR}=3 \cdot 7,95 \% \mathrm{CI}=1 \cdot 2-11 \cdot 1$ ).

Because of over-representation of the FC31 complotype in the patients, it was necessary to see if this was due to linkage disequilibrium with either HLA-B27 or any other HLA-B allele. Table 3 shows the most common class $I$ and class III MHC haplotypes and their corresponding delta values. The increase in FC31 cannot be explained by increase in any HLA-B

Table 1 Phenotype frequencies ( $p f$ ) of relevant $H L A-B$ and complotypes in patients with seronegative spondyloarthropathies and normal controls

\begin{tabular}{|c|c|c|c|c|c|}
\hline & $\begin{array}{l}\text { Patients } \\
(n=100) \\
p f\end{array}$ & $\begin{array}{l}\text { Controls } \\
(n=85) \\
p f\end{array}$ & $p_{\text {corr. }}$ & OR & $95 \% C I$ \\
\hline \multicolumn{6}{|l|}{ HLA } \\
\hline B27 & 0.550 & 0.035 & $<1 \times 10^{-5}$ & $33 \cdot 4$ & $9 \cdot 3-142 \cdot 0$ \\
\hline B14 & $0 \cdot 110$ & $0 \cdot 105$ & NS & $1 \cdot 0$ & $0 \cdot 3-2 \cdot 9$ \\
\hline B57 & 0.090 & 0.058 & NS & $1 \cdot 5$ & $0.4-5 \cdot 7$ \\
\hline B49 & $0 \cdot 130$ & 0.035 & NS & $4 \cdot 0$ & $1 \cdot 0-18 \cdot 7$ \\
\hline B51 & $0 \cdot 180$ & 0.235 & NS & $0 \cdot 7$ & $0 \cdot 3-1 \cdot 5$ \\
\hline B39 & $0 \cdot 110$ & $0 \cdot 270$ & NS & $0 \cdot 3$ & $0 \cdot 1-0 \cdot 7$ \\
\hline B60 & $0 \cdot 120$ & $0 \cdot 152$ & NS & $0 \cdot 7$ & $0.3-1.9$ \\
\hline \multicolumn{6}{|c|}{ Complotypes } \\
\hline FC31 & $0 \cdot 250$ & 0.094 & 0.04 & $3 \cdot 2$ & $1 \cdot 2-8 \cdot 3$ \\
\hline SC30 & $0 \cdot 140$ & 0.117 & NS & $1 \cdot 2$ & $0 \cdot 4-3 \cdot 1$ \\
\hline SC31 & 0.680 & $0 \cdot 788$ & NS & 0.5 & $0 \cdot 2-1 \cdot 1$ \\
\hline
\end{tabular}

$p_{\text {corr: }}: p$ corrected for number of comparisons.

NS: Not significant.

Table 2 Phenotype frequencies ( $p f$ ) of relevant $H L A-B$ and complotypes in $H L A-B 27$ negative patients with seronegative spondyloarthropathies and normal control

\begin{tabular}{|c|c|c|c|c|c|}
\hline & $\begin{array}{l}\text { Patients } \\
H L A-B 27(-) \\
(n=45) \\
p f\end{array}$ & $\begin{array}{l}\text { Controls }^{\star} \\
H L A-B 27(-) \\
(n=82) \\
p f\end{array}$ & $p_{c o r}$ & $O R$ & $95 \% C I$ \\
\hline \multicolumn{6}{|l|}{ HLA } \\
\hline B14 & $0 \cdot 177$ & $0 \cdot 109$ & NS & $1 \cdot 7$ & $0 \cdot 5-5 \cdot 4$ \\
\hline B57 & 0.133 & 0.060 & NS & $1 \cdot 4$ & $0.5-9 \cdot 6$ \\
\hline B49 & 0.200 & 0.036 & 0.03 & 6.5 & $1.5-32 \cdot 8$ \\
\hline B51 & 0.222 & 0.243 & NS & 0.8 & $0 \cdot 3-2 \cdot 2$ \\
\hline B39 & $0 \cdot 244$ & $0 \cdot 280$ & NS & 0.8 & $0 \cdot 3-2 \cdot 0$ \\
\hline \multicolumn{6}{|c|}{ Complotypes } \\
\hline FC31 & $0 \cdot 288$ & 0.097 & 0.04 & $3 \cdot 7$ & $1 \cdot 2-11 \cdot 1$ \\
\hline SC 30 & 0.044 & $0 \cdot 121$ & NS & 0.3 & $0.04-1.5$ \\
\hline SC31 & 0.644 & 0.788 & NS & 0.5 & $0 \cdot 2-1 \cdot 2$ \\
\hline
\end{tabular}

$\mathrm{p}_{\text {corr. }}$ p corrected for number of comparisons. significant.

$\star$ Excluding HLA-B27 $(+)$ individuals $(\mathrm{n}=3)$.

Table 3 Linkage disequilibrium (delta values) between $H L A-B$ and complotypes in patients with seronegative spondyloarthropathies

\begin{tabular}{lllll}
\hline Haplotype & $\begin{array}{c}\text { Expected } \\
\text { frequency }\end{array}$ & $\begin{array}{l}\text { Observed } \\
\text { frequency }\end{array}$ & $\begin{array}{l}\text { Delta } \\
\text { value }\end{array}$ & $p$ \\
\hline [B27;SC33] & 0.022 & 0.055 & 0.019 & 0.0005 \\
[B27;FC31] & 0.040 & 0.060 & 0.0125 & NS \\
[B14;FC31] & 0.006 & 0.005 & -0.001 & NS \\
[B39;FC31] & 0.008 & 0.020 & 0.005 & NS \\
[B57;FC31] & 0.006 & 0.010 & 0.002 & NS \\
[B49;SC31] & 0.028 & 0.025 & -0.205 & NS \\
[B14;SC31] & 0.024 & 0.025 & -0.0002 & NS \\
[B39;SC42] & 0.005 & 0.015 & 0.004 & 0.05 \\
\hline
\end{tabular}

allele. The same table shows that only two haplotypes showed linkage disequilibrium, namely B27-SC30 $(p=0.0005)$, and B39-SC42 $(\mathrm{p}=0.05)$.

\section{Discussion}

As for most populations worldwide, we found a significant increased frequency of HLA-B27 in patients with SSpA. Patients who lack this antigen showed instead, a significant increase in HLA-B49. Regardless of the presence of B27, an increase in the FC31 complotype was also found, suggesting that besides the HLA-B27 antigen additional genes might also be involved in the susceptibility to develop SSpA.

Previous reports dealing with complotypes focused only on AS B27 positive individuals. ${ }^{25} 26$ As our study was not restricted to this disease or to any HLA-B antigen, we were able to gain a better insight into the role of complotypes.

Previous studies in B27-negative patients showed association with HLA-B16. ${ }^{27} 28$ This was followed by reports on an increased frequency of HLA-B22 $2^{29}$ and HLA-B7, ${ }^{30}$ suggesting a 'public' antigen of the HLA-B27 CREG group (HLA-B7, $\mathrm{Bw} 22, \mathrm{~B} 27, \mathrm{~B} 40$ and B42) (unpublished) in addition to $B 16$. Others ${ }^{28} 3132$ have found association of Bw62 and B35. Our study adds the B49 antigen to the list of HLA-B alleles associated with SSpA.

The mechanisms whereby the MHC class I antigen HLA-B27 confers susceptibility to AS and RS remain unknown. One hypothesis is that binding of bacterial-derived or autologous 'arthritogenic peptides', or both, to the HLA-B27 molecule could induce CD8 cytotoxic $T$ lymphocytes as a crucial event in the initiation of reactive arthritis and other spondyloarthropathies. ${ }^{33}$ If this is correct, it is possible that other antigens with the same characteristics of binding may induce the cytotoxic response, and one of them could be the B49 antigen. Sequence analysis of this antigen and its comparison with HLA-B27 sequences is required to confirm this hypothesis.

Our report is one of the few studies that suggest a possible role of additional genes besides B27 in the genetic susceptibility to develop SSpA. The most interesting part of this issue is the relatively high incidence of the FC31 complotype, regardless of the presence of HLA-B27. Interestingly, the complotype was not found in linkage disequilibrium with B27 or any other HLA-B antigen (table 3 ). We assume that the FC31 complotype could be in linkage disequilibrium with other markers within the MHC region. Candidates for such a role are probably the TAP genes which code for the protein transporters of peptides to the endoplasmic reticulum and are directly related with antigen processing. ${ }^{34-37}$

These results suggest that in Mexican mestizo patients with SSpA, other genetic factors in addition to B27 are associated with the disease expression, and these include the FC31 complotype.

Our results suggest that some of the additional genes (other than B27) that predispose to SSpA, might also reside in the MHC region. These data emphasise that SSpA have a multifactorial 
aetiology which includes a variety of genetic predisposing factors. Identification of complementary alleles involved in increasing susceptibility to SSpA may provide important clues to understanding the pathogenesis of the disease, and may help uncover environmental factor(s) that trigger it in genetically susceptible individuals.

This work was supported in part by grants from the Consejo Nacional de Ciencia y Tecnologia, México, and the Program Universitario de Investigación en Salud, Universidad Nacional Autónoma de México.

1 Schlosstein L, Terasaki P I, Bluestone R, Pearson C M. High association of an HL-A antigen W27 with ankylosing spondylitis. N Engl f Med 1973; 288: 704-6.

2 Brewerton D A. HLA-B27 and the inheritance of susceptibility to rheumatic diseases. Arthritis Rheum 1976 19: $656-68$.

3 Woodrow J C. Histocompatibility antigens and rheumatic diseases. Semin Arthritis Rheum 1977; 6: 257-76.

4 Khan M A, Khan M K. Diagnostic value of HLA-B27 testing in ankylosing spondylitis and Reiter's syndrome. Ann Intern Med 1982; 96: 70-6.

5 Calin A, Fries J F. Striking prevalence of ankylosing spondylitis in "healthy" W27 positive males and females. spondylitis in "healthy" W27 posit

6 Khan M A, Kellner H. Immunogenetics of spondyloarthropathies. Rheum Dis Clin North Am 1992; 18: arthropa $837-64$.

7 Khan M A. Ankylosing spondylitis and heterogeneity of HLA-B27. Semin Arthritis Rheum 1988; 18: 134-41.

8 Choo S Y, Antonelli P, Nisperos B, Nepom G T, Hanson J A. Six variants of HLA-B27 identified by isoelectric focusing. Immunogenetics 1986; 23: 24-9.

9 Breur-Vriesendorp B S, Dekker-Saeys A J, Ivanyi P. Distribution of HLA-B27 subtypes in patients with ankylosing spondylitis: the disease is associated with a common determinant of the various B27 molecules. Ann Rheum Dis 1987; 46: 353-6.

10 Hill A V S, Allsopp C E M, Kwiatkowski D, Anstey N M Greenwood B M, McMichael A J. HLA class I typing by PCR: HLA-B27 and an African B27 subtype. Lancet 1991; 337: 640-2

11 Stein $M$, Davis P, Emmanuel J, West G. The spondyloarthropathies in Zimbabwe: A clinical and immunogenetic profile. F Rheumatol 1990; 17: 1337-9.

12 Lisker R, Pérez Briceño R, Granados J, et al. Gene frequencies and admixture estimates in a Mexican city population. Am $\mathcal{A}$ Physical Anthropol 1986; 71: 203-7.

13 Lisker R, Pérez Briceño R, Granados J, Babinsky V. Gene frequencies and admixture estimates in the state of Puebla, México. Am 7 Physical Anthropol 1988; 76: $331-5$.

14 Lisker R, Ramirez E, Pérez Briceño R, Granados J, Babinsky $V$. Gene frequencies and admixtures estimates in four mexican urban centers. Hum Biol 1990; 62: 791-801.

15 Robinson W P, Van Der Linden S M, Khan M A, et al. HLA-Bw60 increases susceptibility to ankylosing spondylitis in HLA-B27 + patients. Arthritis Rheum 1989; 32: $1135-41$.

16 Dougados M, Van Der Linden S, Juhlin R, et al. The European Spondylarthropathy Study Group preliminary criteria for the classification of spondylarthropathy. Arthritis Rheum 1991; 34: 1218-27.
17 Bennet P H, Burch T A. Proc 3rd international symposium on population studies of the rheumatic diseases, New York, 1966. In: Bennet P H, Wood P H N, eds. Amsterdam: Excerpta Medica Foundation, 1968: 305-13.

18 Willkens R F, Arnett F C, Bitter T, et al. Reiter's syndrome: evaluation of preliminary criteria for definite disease. Arthritis Rheum 1981; 24: 844-9.

19 Boyum A. Isolation of leukocytes from human blood: further observations. Scand $\mathcal{f}$ Clin Lab Invest (Suppl) 1968; 97: 31 .

20 Terasaki P I, McClelland J D. Microdroplet assay of human serum cytotoxins. Nature 1964; 204: 998

21 Alper C A, Boenisch T, Watson L. Genetic polymorphism in human glycine-rich beta-glycoprotein. 7 Exp Med 1972; 135: $68-80$.

22 Awdeh Z L, Alper C A. Inherited structural polymorphism of the fourth component of human complement. Proc Natl Acad Sci USA 1980; 77: 3576-80

23 Alper C A. Inherited structural polymorphism in human $\mathrm{C} 2$ : evidence for linkage between $\mathrm{C} 2$ and $\mathrm{BF} .7 \mathrm{Exp} M e d$ 1976; 144: 1111-5.

24 Mattiuz P, Ihde D, Piazza A, Cepellini R, Bodmer W F. New approaches to the population genetic and segregation analysis of the HLA system. In: Terasaki P I, ed. Histocompatibility testing. Copenhagen: Munksgaard, 1970: 193-205.

25 Gran J T, Teisberg P, Olaissen B, Thorsby E, Husby G. HLA-B27 and allotypes of complement components in ankylosing spondylitis. 7 Rheumatol $1984 ; 11$ : 324-6.

26 Lochead J A, Chalmers I M, Marshall W H, et al. HLA-B27 haplotypes in family studies of ankylosing spondylitis. Arthritis Rheum 1983; 26: 1011-6.

27 Van Der Berg-Loonen E M, Decker-Saeys B J, Meuwiesen S G M, Nijenhuis L E, Engelfriet C P. Histocompatibility antigens and other genetic markers in ankylosing spondylitis and inflammatory bowel diseases. $f$ Immunospondylitis and inflammatics
genetics $1977 ; 4: 167-75$.

28 Khan M A, Kushner I, Braun W E. Genetic heterogeneity in primary ankylosing spondylitis. If Rheumatol 1980; 7: 383-6.

29 Safwenberg J, Domeij-Nyberg B, Kjallmann M. HLA antigens in females with ankylosing spondylitis and other forms of seronegative rheumatic diseases. Scand $f$ Rheumatol 1978; 7: 177-82.

30 Khan M A, Kushner I, Braun W E. A subgroup of ankylosing spondylitis associated with HLA-B7 in American blacks. Arthritis Rheum 1978; 21: 528-30.

31 Wagener $P$, Zeidler $H$, Eckert $G$, Deicher $H$. Increased frequency of HLA-Bw62 and Bw35 CREG antigens in HLA-B27 negative ankylosing spondylitis. $Z$ R Rheumatol HLA-B27 negative

32 Arnett F C, Hochberg M C, Bias W B. Cross-reactive HLA antigens in B27 negative Reiter's syndrome and sacroiliitis. Fohns Hopkins Medical foumal 1977; 141: 183-97.

33 Benjamin R J, Parham P. Guilt by association: HLA-B27 and ankylosing spondylitis. Immunol Today 1990; 11: $137-42$.

34 Deverson E V, Gow I R, Coadwell W J, Monaco J J, Butcher GW, Howard J C. MHC class II region encoding proteins related to the multidrug resistence family of transmembrane transporters. Nature 1990; 348: 738-41.

35 Monaco J J, Cho S, Attaya $M$. Transport protein genes in the murine MHC: possible implications for antigen the murine MHC: possible implication

36 Spies T, Bresnahan M, Bahram S, et al. A gene in the human major histocompatibility complex class II region controlling the class I antigen presentation pathway. Nature 1990; 348: 744 7 .

37 Monaco J J. A molecular-model of the MHC class I restricted antigen processing. Immunol Today 1992; 13: 173-8. 